\title{
Am I Interfering? Preschool Teacher Participation in Children Play
}

\author{
Chia-Yen Tsai \\ Department of Early Childhood Education, National Dong Hwa University, Taiwan
}

Copyright (C) 2015 by authors, all rights reserved. Authors agree that this article remains permanently open access under the terms of the Creative Commons Attribution License 4.0 International License

\begin{abstract}
This study aimed to explore the timing and strategies of teacher participation in children's play and the factors which have a bearing on teacher participation. This study used qualitative research and conducted observation of natural situations. The samples were preschool teachers in an elementary school's affiliated kindergarten in Hualien. The children were observed while playing at learning areas during free play time. In order to enhance the depth of the research, data were collected from observations of play, interviews with the teacher, and examination of on-site documents. The results of qualitative analysis revealed that preschool teachers usually intervene in children's play actively. Preschool teachers used different strategies depending on the different behavior of children play. As for whether or not to participate; these depend on the teacher's educational philosophy, degree of familiarity with the children, and the overall situation in which the play is occurring. Moreover, each of these factors influences one another, and thus need to be considered together.
\end{abstract}

Keywords Preschool, Teachers' Participation, Children's Play

\section{Introduction}

There is a long-standing controversy as to the desirability of teacher participation in children's play. In the post-modern view of education, children should be encouraged to decide for themselves which activities to engage in and which profession to pursue, such that excessive guidance by teachers amounts to interference and is to be avoided (Brown \& Freeman, 2001). Bennett, Wood, and Rogers (1997) encouraged teachers to avoid interfering in their children's play, in the belief that independent play brings the most benefit. Indeed, many teachers regard certain forms of participation as interference (Korat, Bahar, \& Snapir, 2003). Other preschool teachers, however, agree with Vygotsky's view that teachers should apply scaffolding to children's play and encourage them to engage in more complex activities (Bodrova \& Leong, 2006). Related research has found that teacher participation in children play promotes a positive children-teacher relationship (Driscol \& Pianta, 2010), enriches the children's learning, and enhances the development of cognitive, verbal, creative, and social skills (Bennet, Wood, \& Rodgers, 1997; Howes, Burchinal, Pianta, Bryant, Early, Clifford, \& Barbarin, 2008; Smilansky \& Shefatya, 1990). According to this school of thought, not participating in children play and play amounts to missing a key opportunity to promote the development of important skills amongst preschoolers (Trawick-Smith \& Dziurgot, 2011).

Other researchers have pointed out that the influence of teacher participation in children play can be either positive or negative, depending on how it is carried out. Similarly, Frost, Wortham, and Reifel (2005) found that excessive teacher participation is seen as intrusive by children and lessens their interest in the activity. Moreover, teacher participation often gives undue stress to an intellectual understanding of the game being played (Cimitrova \& Gimitrova, 2003). In light of the points of view presented above, effective participation entails more than simply playing together with children or simultaneously guiding the activity, for teacher participation can have a positive influence only if the teacher is sufficiently sensitive to the situation to provide a suitable learning scaffold (Berk, 1994; Bodrova \& Leong, 2003). For example, in the case of children who are onlookers, tend to play by themselves, have little interaction with others, or who do participate in play but have difficulty cooperating with others, appropriate teacher intervention can increase the child's social skills and level of participation (Smilansky \& Shefatya, 1990; Teawick-Smith, 1994). Furthermore, it would be desirable for a teacher to encourage the child who tends to only play repetitive, simple, or solitary games to engage in more complex, challenging, and group play. Of course, the optimal opportunity for effective participation arises when the child himself invites the teacher's participation (Johnson, Christie, \& Yawkey, 1999).

According to Bodrova and Leong (2007), effective participation in relatively complex play includes providing suggestions for elaborating the theme of the play; conflict 
resolution; encouraging cooperative behavior; adding new teams; and accepting new points of view. Inasmuch as teacher participation is mainly for the purpose of assisting and enriching children play, children more adept at play require less teacher participation. However, with children who are overly reliant on the teacher and frequently ask the teacher to join their play, the teacher needs to adjust the scaffold in a timely manner, and also encourage them to participate in play with their classmates (Trawic-Smith, 1994). It is also desirable to flexibly employ a variety of scaffolds in accordance with the situation, including verbal cues, examples, and collaboration (Chou, 2013). Furthermore, teachers need to adjust their manner and degree of participation in accordance with the situation and receptiveness of the children. Shin and Spodek (1991) asserts that appropriate teacher behavior during the planning stage includes guidance, dialogue, and encouragement, rather than modeling, participation, and directing; and that appropriate teacher behavior while the play is in process includes dialogue, adjusting the surroundings, and reminders, rather than guidance, lectures, and directing.

From the studies mentioned above it can be seen that teachers do need to participate in their children's play, but only in an appropriate manner based on a good understanding of the needs of the actual situation. Indeed, excessive participation or guidance deprives children of the opportunity to learn for themselves. Conversely, if guidance is required, but comes too late or not at all, then an important learning opportunity will be missed. While previous studies have covered such aspects of teacher participation in children play as timing (Kontos, 1999) and its influence on children development (Enz \& Christie, 1997), they have mainly adopted a quantitative methodology and fail to give due consideration to the participation process itself (Kontos, 1999; Shin \& Spodek, 1991; Trawick-Smith \& Dziurgot, 2011). Moreover, the studies that do discuss the strategies of participation fail to investigate the factors which have a bearing on teacher participation. Thus the present study covers not only the timing and strategies of teacher participation in children's play, but also the factors which have a bearing on teacher participation.

\section{Methods}

\section{Settings}

This study was carried out at a preschool affiliated with an elementary school in Taiwan's Hualian County. At the time of the study the preschool had two classes: one for five-year-olds, and one for three-, and four-year-olds. This research was mainly carried out with the younger class, which had 16 children, ten of whom were four years of age, and six of whom were three years of age. The preschool's free play period is held every morning from 10:00 to 10:30 in the classroom's "learning areas." The learning areas consisted of four partitioned areas for particular activities, including a doll area, a manipulative area, an art area, and a language area.

\section{Participants}

In this study I investigate how and why preschool teachers participate in their children' play. Thus it was necessary to first find preschools with a learning area and teachers who participate in their children' play. Presently many preschools have learning areas and give considerable emphasis to theme-based learning. However, many of these learning areas are only used to fill out the school day, or are only open at the very beginning or end of the day, which doesn't provide sufficient time for the children to fully engage in free play. As a result, after consulting with a number of scholars and preschool teachers, it was determined that Ms. Li was the only suitable teacher willing to participate in this study.

Ms. Li, who participated in this study, holds a graduate degree from an early childhood education program at a public university in Taiwan. At the time of the study she had two years of teaching experience and had been teaching at the participating preschool since 2011. Although she only had two years of full-time teaching experience, during graduate school she taught part-time at a preschool.

\section{Collecting and analyzing the data}

During the course of the research I observed Ms. Li and her children two times per week during the free-play period; the total number of observations was 30 . Prior to carrying out the research, I explained the research project to Ms. Li and the preschool director and secured their agreement to participate. I made video recordings of each free-play period observed. Before making the actual observations, I conducted a pilot observation in which I filmed a free-play period so as to get the children accustomed to my presence.

The data collected consisted of the video recordings, interviews, and secondary data. After transcribing the recordings of the free-play periods and interviews, the transcripts were repeatedly read through so as to ascertain the sections which illustrated the teacher-children relationship. The key themes and concepts found in these sections where then encoded and compared. Finally, the data was organized and categorized.

\section{Research Ethics}

Prior to conducting the observations, I explained the purpose and background of the study to the participant and requested permission to make audio-visual recordings, thereby establishing trust and a solid relationship with the participant. Furthermore, I informed the participant that her participation would be kept completely anonymous and that her identity would not be revealed at any time. I also informed her that the data gathered in the course of this research would only be used for the purposes of this study, and would be destroyed upon completion of the study.

\section{Results and Discussion}




\section{A. The teacher's timing and strategies of participation}

The learning area was open during the free play period, and this is when the teacher would assume various roles in the children's play in accordance with the situation. The findings were as follows:

\section{Assistance and guidance in response to children requests}

During the free-play period, children would occasionally encounter difficulties and request help from the teacher or their classmates. Ms. Li stated that in such a situation, rather than always providing immediate assistance, she first assesses the situation based on the children's past behavior and her knowledge of his ability. For example, a child playing in the toy area who wanted to put on a dinosaur costume which had to be fastened on by tying a knot on the strap asked: "Teacher, can you help me tie a knot?" After Ms. Li tied on the costume, the child went on his way and proceeded to put on the dinosaur head. At other times, however, she takes a more indirect approach, providing step-by-step guidance which helps the children to observe the problem, consider possible solutions, and finally solve the problem for himself. it.

C: Teacher, I don't know how to play baseball; I can't do

T: Well then, let's do it together! Okay?

C: Okay.

T: Now, take a look. Where does this go? Like this? Give it a try.

C: Here; it's here. Look.

$\mathrm{T}$ : These yellow straws, how many are there?

C: One, two, three, four, five.

T: Five yellow ones; you have five yellow straws.

$\mathrm{C}$ : What about the orange ones?

$\mathrm{T}$ : These are the yellow ones; pick up the yellow ones.

C: I've picked them up.

T: Five. Okay, now you count them.

C: One, two ...

The teacher participation in children play has a positive effect only when the teacher is sufficiently sensitive to provide a suitable scaffolding (Berk, 1994; Bodrova \& Leong, 2003; Smilansky \& Shefatya, 1990). Thus, prior to participating, the teacher needs to first observe the situation, while keeping in mind the children's character and ability; for only after doing so will the teacher be able to participate in such a way as to enhance the children's ability.

\section{Responding to children requests by spontaneously participating}

The children playing in the doll area were more likely to invite the teacher to participate in their play. Because they were relatively familiar with the materials in the doll area, the children tended to quickly select a toy or costume and then invite the teacher to participate in their play. For example, the children often use the materials they find there to open a shop and then pretend to be the shopkeeper. When they ask Ms. Li what she would like to eat, she joins the children's play by asking for more information about the shop and what it sells. The teacher assumes the role of a customer in the child's make-believe store.

C: What would you like to eat?

T: What kind of store do you have? What do you sell? Do you sell fruit?

C: Um, whatever you want, I have it.

T: Since you have everything, I think I'll have a kiwi fruit.

C: Kiwi? Wait a moment.

In such situations Ms. Li adopts an appropriate role and simply goes along with the scenario thought up by the child, giving the child free rein to direct the plot as he or she wishes, while being careful not to interfere with the children's play.

\section{Reminding children to follow the rules governing classroom play}

While enjoying their time in the learning area, the children are also expected to follow the rules governing classroom play, so that they don't interfere with others' play and don't injure themselves or others. However, sometimes the children are having so much fun and become so deeply immersed in their play that they forget about these rules and start engaging in such forbidden behavior as chasing each other around the classroom. At such times $\mathrm{Ms}$. $\mathrm{Li}$ participates by stopping the play and asking the child to calm down and review the rules governing the behavior in question:

(Two children, toys in hand, are running around the classroom. After making two circuits of the classroom, one of them collides with a student who is sitting down playing a game, but just continues running as if nothing has happened.)

T: Just now, didn't you collide with Amy?

$\mathrm{C}$ (nods in agreement).

$\mathrm{T}$ : Is that kind of running around permitted in the classroom?

C (shaking head): No.

$\mathrm{T}$ : Please remember that.

C (shakes head).

$\mathrm{T}$ : Running around like that is very dangerous; you might crash into someone. You forgot to say "sorry" to Amy.

C: (turning towards Amy) Sorry.

T: Please walk, and do so carefully. When you're having fun you have to remember to be careful.

Because she is working with the younger children, Ms. Li makes it a point to frequently remind them of the rules governing classroom behavior and the free-play period, so that early on they cultivate an awareness of the conduct that is expected of them.

\section{Teacher mediation in kid conflicts}

Due to differences of opinion and poor communication skills, there sometimes arise conflicts between children which bring the play to a premature halt. Many of these conflicts arise in relation to two or more children contending 
for the same toys. In such situations Ms. Li first ascertains the nature of the problem and then helps the children find a solution. However, if any of the children involved stubbornly refuse to compromise, then she participates by mediating the dispute and giving further suggestions for finding a resolution. One time two kids (B and $\mathrm{G}$ ) began to shout and scream as they contended for the same toy:

T: Who did that just now? G, was it you?

B (lowers head, remains silent, and tightly grips the toy in his hand).

T: So, you can play with G.

B (still silent, but loosening his grasp on the item he has made).

T: You see, he is letting go of it. Now G, you can make another one, okay? You already know how to do it.

Preschool teachers need to give special attention to classroom safety. However, when children are playing together, various types of conflict inevitably arise. If any of the children involved lack self-control or are extremely egocentric, such conflicts can result in physical or emotional harm. Thus some researchers maintain that such conflicts require swift participation on the part of the teacher (Bodrova \& Leong, 2007; Trawick-Smith \& Dziurgot, 2011).

\section{Teacher-initiated participation in educational play}

Ms. Li has an extensive knowledge of educational concepts which she applies not only to preplanned lessons, but also to a wide variety of situations that spontaneously arise. While the children are playing, as long as the overall situation is conducive, she frequently takes the opportunity to bring up something she has previously taught, thereby having the children review and apply what they have already learned. For example, she once conducted an impromptu math review as follows:

C: Teacher, count these.

$\mathrm{T}$ : There are so many.

C: Not really; 1, 2, 3, 4, 5 (counting a group of sequins with one finger).

Also, Ms. Li often has her children engage in impromptu language lessons, especially reviews relating to Mandarin phonetic symbols (the phonetic symbols used in Taiwan to indicate the Mandarin pronunciation of Chinese characters). For example, the following dialogue occurred while a child was in the language area playing with a device which helps children practice their recognition of phonetic symbols:

T: Spot test!

$\mathrm{C}$ (nods in agreement).

$\mathrm{T}$ : Listen closely (pressing the button which produces the sound "eng").

C: It's "eng" (pressing the button which produces the sound "eng").

T: Next (pressing the button for " $j i$ ").

$\mathrm{C}$ : It's "ji." (pondering while hovering his finger over the button for "ge").

T: No, that one is "ge."
C: This isn't "ji." (Then suddenly pointing to “yi") It's "yi."

From the children's response it appears that he had only a rudimentary knowledge of Mandarin phonetic symbols, or may have never learned them at all. Thus Ms. Li's spot quiz may have made the child feel frustrated, thereby ruining the fun the child was having simply playing around with an amusing toy. As Gimitrova and Gimitrov (2003) points out, teacher participation often places too much stress on the cognitive aspect of play.

\section{The teacher asks the child about something he has made}

Children enjoy making things, but the things they create don't necessarily bear a close resemblance to the objects they are modeled on; for children often rely on their fertile imaginations to whimsically create things they find appealing. In such type of play children often use miniature versions of real objects, and Ms. Li encourages reflection by asking questions about what has been created, as in the following interaction:

$\mathrm{T}$ : Can your pistol be held in one hand?

C: You have to hold it with two hands.

T: Pistols are held with one hand; can you do it? How do you fire it? Where is the trigger?

C: Um, it's here.

$\mathrm{T}$ : So, can you fire it? Or is there another trigger somewhere?

In fact, there were quite a few situations in which the teacher would initiate participation in the children's play so as to enhance the educational value of the play, typically after asking some questions to ascertain the nature of the game being played or the object being made. Sometimes, however, she would take the initiative to remind the students about the classroom rules or the rules of the game being played, or even stop children who were running around and disturbing others. Similarly, Logue and Harvey (2010) found that when children' play was getting dangerously out of hand, teachers would choose to put a stop to it out of consideration for classroom safety. In the present study it was also found that the teacher often assisted the children by asking questions and providing guidance and hints. Similarly, Trawick-Smith and Dziurgot (2011) found that teachers tend to influence student play directly through the use of reminders and questions, and indirectly through the use of hints. Yet, upon taking a closer look at the questions asked and how the guidance is provided, it can be seen that oftentimes the teacher's participation is directed towards a certain goal and that teachers find it hard to stay in the background. In this connection, Knotos and Keys (1999) found that when teachers actively participate in children play and expect the play to have a particular outcome, this gives rise to a negative kind of relationship with the students. This was not found in the present study, perhaps because the purpose was different, resulting in a lack of emphasis on how teacher interference influences children. However, it was found that 
the children in the present study did not welcome a high degree of teacher participation in their play.

\section{B. Factors influencing teacher participation}

\section{Teacher's views on education}

All teachers have limitations in their professional abilities, and from time to time they encounter difficulties. Moreover, children are just beginning to develop the many abilities essential to getting along in life. Ms. Li stated that one of her roles is to help her children to develop these abilities:

Even adults encounter things they don't know how to do. So I feel that a teacher needs to be there for them, to teach them, to guide them. I feel that it's often necessary to participate in their play. If I just let them play on their own, then they might not make any progress.

Thus Ms. Li believes that it's necessary to provide a certain amount of timely and appropriate guidance when her children are playing. For by doing so their play become more conducive to the development of essential abilities, the acquisition of which provide children with a sense of accomplishment.

\section{Teacher expectations and level of familiarity with children}

The children began playing with the toys they found interesting, Ms. Li's participation helped her to discover a lot about each children's personality, including their differing levels of interest in group activities. In this regard she stated:

If the entire day is spent in class together, then I would have fewer opportunities to learn about their individual personalities. But by participating in their activities during the free-play period I have learned a lot about their different characters and how they think.

Moreover, Ms. $\mathrm{Li}$ indicated that if she notices that during the free-play period a kid always plays with the same toy in the same way, then she adopts various strategies for encouraging some variation, about which she stated:

I don't directly tell him to play in a different way or to play with something different. What I do is to set an example and see if he will follow it.

Ms. Li indicated that in the case of a kid who tends to only play simple, repetitive, or solitary play, she tries to encourage him to play group games or play which are more complex. An optimal opportunity for effective participation arises when the child himself invites the teacher's participation (Johnson, Christie, \& Yawkey, 1999).

\section{The requirements of the situation}

Ms. Li participated most frequently in the arts area (38.7\%), followed by the manipulative area $(33.7 \%)$, doll area $(18.6 \%)$, and language area $(9.0 \%)$. The main reason for her giving relatively more attention to the arts and manipulative areas was that she had added some new materials to these two areas. Even though she had already taken time during class to introduce these materials and demonstrate how to use them, she was still concerned that some of the children didn't fully understand. In addition, she also wanted to find out how the children would play with these new materials.

Similarly, Knotos (1999) found that preschool teachers spend more time participating in children's constructive and manipulative play, and Shin and Spodek (1991) found that preschool teachers spend more time in the arts area. The probable factors which lead teachers to spend more time in these areas include how the learning areas are categorized, the materials included therein, and the children's ages and experience. Such learning areas typically include materials which require some guidance from the teacher.

\section{Conclusions}

Preschool teachers usually intervene in children play on their own volition. The main reasons they participate include children behavior which contravenes classroom rules, fighting between children, an opportunity to carry out milieu teaching, and a desire to gain a better understanding of their children. Because fighting and the breaking of classroom rules can result in children being injured, in such cases teachers need to intervene by mediating, reminding children of the rules, and encouraging them to reconsider their behavior. However, with respect to milieu teaching and a desire to gain a better understanding of one's children, even if the teacher does make a thorough observation of the situation before participating, she still needs to fully consider the influence such participation will inevitably have on the child's play.

In situations where children invite the teacher's participation, it is usually appropriate for the teacher to spontaneously take on a suitable role and join the activity. However, in the case of a kid asking for help in solving a problem, the teacher needs to first consider the children's character and ability, and then offer assistance which suits the children and the situation. As for whether or not to participate; how often to do so; when to do so; and how to do so - these depend on the teacher's educational philosophy, degree of familiarity with the children, and the overall situation in which the play is occurring. Moreover, each of these factors influences one another, and thus need to be considered together.

\section{REFERENCES}

[1] Bennett, N., Wood, L., \& Rogers, S. (1997). Teaching through play: Teacher's thinking and classroom practice. Buckingham, UK: Open University Press.

[2] Berk, L. E. (1994). Vygotsky's theory: The importance of make-believe play. Young Children, 50(1), 30-39.

[3] Bodrova, E., \& Leong, D. (2006). Tools of the mind: The Vygotskian approach to early childhood education (2nd ed.). Columbus, OH: Merrill: Prentice Hall. 
[4] Bodrova, E., \& Leong, D. J. (2003). Chopsticks and counting chips: Do play and foundational skills need to compete for the teacher's attention in an early childhood classroom? Young Children, 58(3), 10-17.

[5] Bodrova, E., \& Leong, D. J. (2007). Tool of mind: The Vygotskian approach to early childhood education ( $2^{\text {nd }}$ ed.). Upper Saddle River, NJ: Prentice-Hall.

[6] Brown, M., \& Freeman, N. (2001). "We don't play that way at preschool": The moral and ethical dimensions of controlling children's play. In S. Reifel \& M. Brown (Eds.), Early education and care, and reconceptualizing play(pp.259-274). New York: JAI.

[7] Chou, S. H. (2013). Play VS. Curriculum: Orientation and implementation of play. Taipei: Psychological Publishing.

[8] Driscol, K. C., \& Pianta, R. C. (2010). Banking time in Head Start: Early efficacy of an intervention designed to promote supportive teacher-child relationships. Early Education and Development, 21(1), 38-64.

[9] Enz, B., \& Christie, J. (1997). Teacher play interaction styles: Effects on play behavior and relationships with teacher training and experience. International Journal of Early Childhood Education, 2, 55-69.

[10] Gmitrova, V., \& Gmitrov, J. (2003). The impact of teacher-directed and child-directed pretend play on cognitive competence in kindergarten children. Early Childhood Education Journal, 30, 241-246.

[11] Howes, C., Burchinal, M., Pianta, R., Bryant, D., Early, D., Clifford, R., \& Barbarin, O. (2008). Ready to learn?
Children's pre-academic achievement in pre-kindergarten programs. Early Childhood Research Quarterly, 23, 27-50.

[12] Johnson, J.E., Christie, J. F., \& Yawkey, T. D. (1999). Play and early childhood development $\left(2^{\text {nd }}\right.$ ed.). New York: Addison Wesley Longman.

[13] Kontos, S. (1999). Preschool teachers' talk, role, and activity settings during free play. Early Childhood Research Quarterly, 14(3), 363-382.

[14] Korat, O. Bahar, E., \& Snapir, M. (2003). Socio-Dramatic play as opportunity for literacy development: The teachers' role. The Reading Teacher, 56, 386-393.

[15] Logue, M. E., \& Harvey, H.(2010). Preschool Teacher's Views of Active Play. Journal of research in childhood education, 24, 32-49.

[16] Shin, E., \& Spodek, B. (1991, April). The relationship between children's play patterns and types of teacher intervention. Paper presented at the annual conference of the American Educational Research Association, Chicago.

[17] Smilansky, S., \& Shefatya, L. (1990). Facilitating play: A medium for promoting cognitive, socioemotional, and academic development in young children. Gaithersburg, MD: Psychosocial \& Educational Publications.

[18] Trawick-Smith, J. (1994). Interactions in the classroom: Facilitating play in the early years. New York: Macmillan.

[19] Trawick-Smith, J., \& Dziurgot, T. (2011). 'Good-fit' teacher-child play interactions and the subsequent autonomous play of preschool children. Early Childhood Research Quarterly, 26, 110-123. 